\title{
Synthesis of the technique of academic architectural drawing and architectural fantasy in composite openings as an invariant of professional training of future architects
}

\author{
Ilias Rafikov ${ }^{1 *}[0000-0003-4768-0974]$ \\ ${ }^{1}$ Kazan State University of Architecture and Engineering, 420043, Zelenaya st., Kazan, Russia
}

\begin{abstract}
The article reveals the compositional specificity of architectural drawing from nature and from the standpoint of including the aesthetic category - «fantastic» in the creative learning process. In this regard, the content, methods and forms of teaching in the variety of compositional solutions of architectural drawing are considered.

Keywords: features of the technique of architectural drawing from nature and «fantasy» art; figurative fantasy thinking; search for compositional choice in the plane of the sheet, creative position.
\end{abstract}

\section{Introduction}

Modern styles and trends in architecture objectively require a rethinking of the professional training of an architect, a change in the student's thinking style, who must master a set of architectural techniques, in particular, related to academic training and fantasy creativity. It is known that many architectural discoveries were created as a result of the fantasy creativity of outstanding architects, whose works became masterpieces of architecture of the 20th century: Frank Gehry «Walt Disney Concert Hall», Los Angeles, «S. Guggenheim Museum in Bilbao», Spain; Zaha Hadid Center for Contemporary Art, Cincinnati, Ohio, USA; Jorn Utzon, Sydney Opera House Building, Sydney, Australia; Eero Saarinen «TWA Terminal at John F. Kennedy Airport, New York, USA, and others.

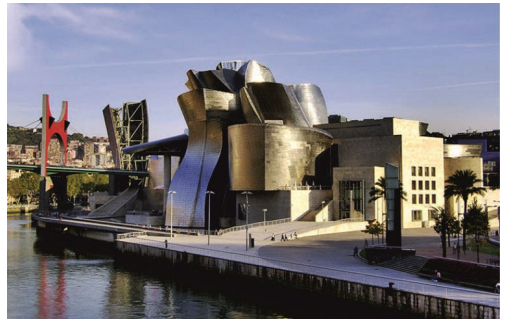

Fig. 1. Walt Disney Concert Hall, Sydney. Architect: Frank Gehry.

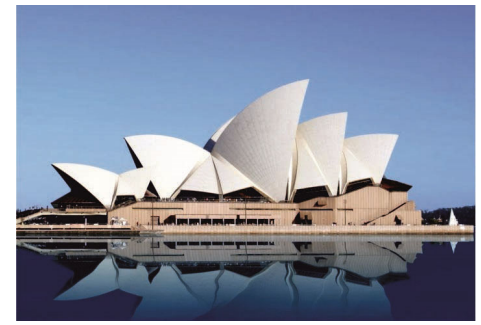

Fig. 2. Opera House Building. Architect: Jorn Utzon.

\footnotetext{
* Corresponding author: ilias.72@mail.ru
} 


\section{Methods}

The process of teaching architectural drawing organically connects images from nature and with «fantasy», designed to develop compositional thinking and form the architect's creative position in creating an architectural image of a particular object.

The scientific and practical basis for the cognition and functional application of architectural drawing from nature and from «fantasy» in their creative interaction essentially comes from understanding and mastering: a specific «language» of graphics (linear relations, reproduction and generalization of the shape of objects, transfer of their illumination, light ratio and shadows, etc.), the «language» of shaping and means of compositional shaping; as well as compositional and artistic thinking.

The academic rules and principles of architectural drawing from nature are aimed at solving certain and clearly defined tasks:

- possession of image techniques of a complex volumetric-spatial form from various angles, changing the horizon line, while maintaining proportional relationships;

- the ability to use the basics of a realistic image: competently build an aerial perspective, correctly build a tonal analysis of objects;

- setting and solving non-standard tasks in drawing a graphic image of the architecture of urban space and interior.

\section{Results}

As an analysis, it is appropriate to refer to the following works. Within the framework of the academic drawing, student work is presented (Fig. 3), revealing in a complex multifigure setting the volume-spatial characteristics of objects, their interposition in space, while observing the regularity of light and shade and the transfer of planning. The linearconstructive drawing of a still life of simple geometric shapes, made from different sides and with different lines of the horizon, is an example of a student's mastering of a perspective image, a composition of simple geometric shapes with given points of perception, while maintaining proportional ratios of individual figures to each other (Fig. 4). In the work «complex still life» (Fig. 5), the student found a successful point of view (the position of the viewer), which gave him the opportunity to unmistakably arrange still life objects on the sheet, with the correct proportional ratios. It should be noted that when working with light-tonal relations, the planning of the drawing is conveyed with the identification of the texture of materials and the shape of still life objects.

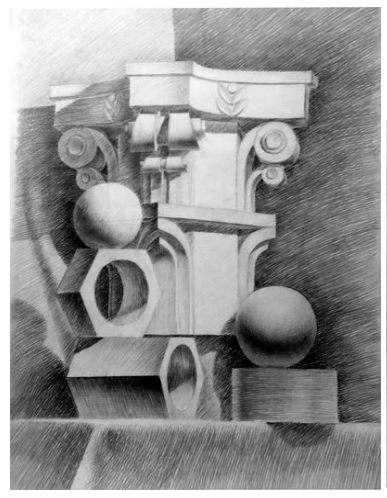

Fig. 3. Natural drawing.

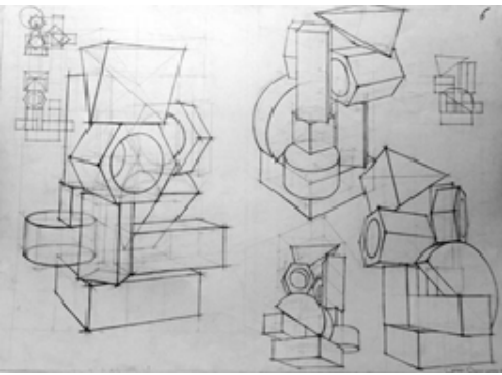

Fig. 4. Drawing by imagination.

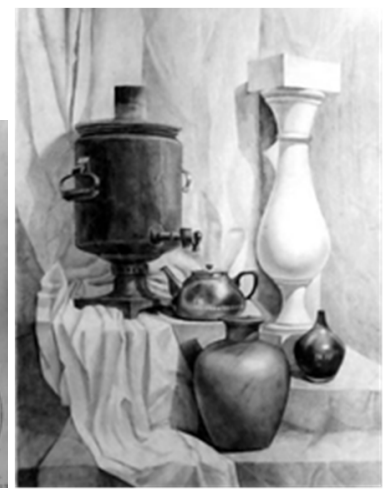

Fig. 5. Natural drawing. 
One of the main tasks in the course of architectural drawing (Fig. 6) is the drawing of architectural structures in the surrounding spatial environment. In this drawing, in the creation of an artistic and expressive image, the knowledge gained over the years of study is fully reflected: the choice of a place and point of view in front of the object; the ability to use airy-linear perspective and a vision of proportions; choice of graphic material; professional mastery of black and white modeling with bright light and strong deep shadows and in all the richness of shades and gradations of chiaroscuro.

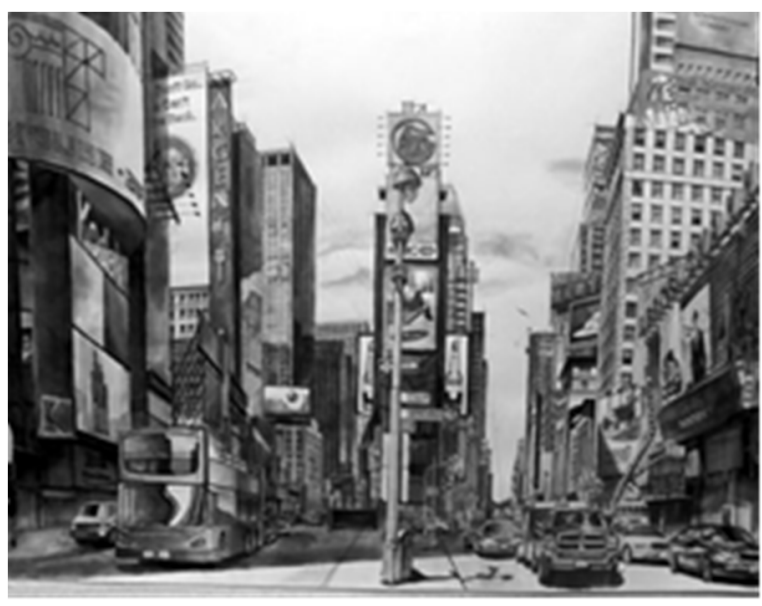

Fig. 6. Natural drawing.

\section{Discussion}

Architectural drawing, including the «fantastic», is associated with a different style of thinking in contrast to the content of classical professional training in the process of teaching academic architectural drawing: the nature of fantasy logically requires a different culture of thinking, in which uniqueness and originality dominate. In the process of solving compositional problems in the classroom on architectural drawing, the fantastic is used by us in the broad sense of the word, having in mind its following meanings as:

- aesthetic perception of the phenomena of reality, the natural world;

- a means of expressing and awakening the creative imagination of future architects;

- teaching technique of artistic variation of a theme related to architectural thinking in solving compositional problems of architectural drawing.

The fantastic in its multivalued content, which has developed in the history of art since ancient times, in the process of teaching architectural drawing expands the boundaries of the creative approach in the choice of compositional solutions, orients to a new way of artistic thinking. In fact, the inclusion of the category of aesthetics - «fantastic» naturally presupposes other forms of education, different conceptual approaches to the training of future architects, which approve the search, experimental findings based on figurativefantasy, artistic thinking, devoid of any kind of imitation and clichés. 


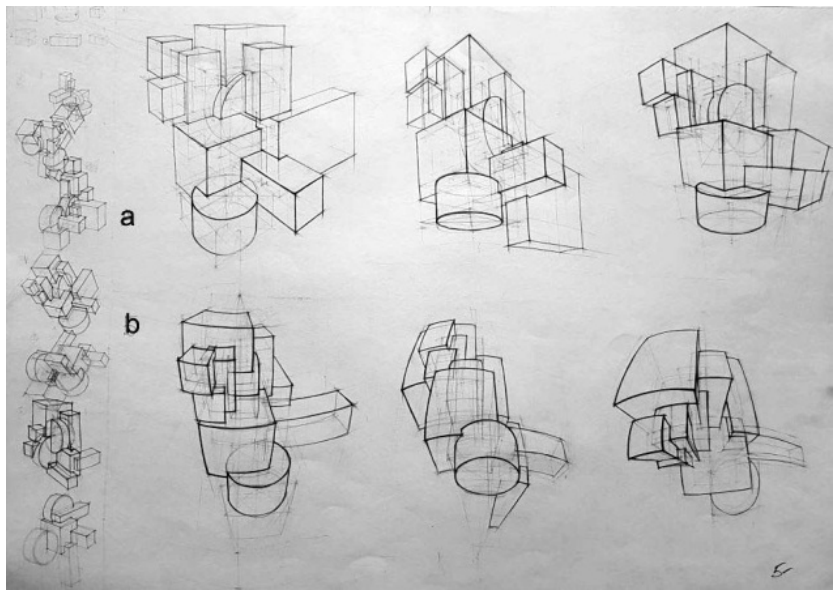

Fig. 7. a, b. Fantasy drawings.

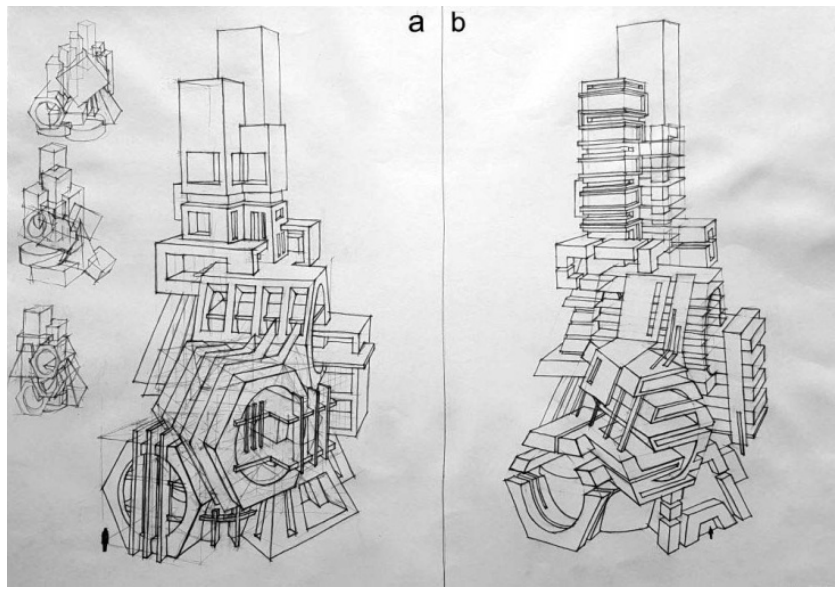

Fig. 8. a, b. Fantasy drawings.

So, in the educational task (Figs. 7. a, b.), students are invited to make up of seven simple geometric shapes: two cylinders, a parallelepiped, two different-scale cubes, two pencil cases different in length to develop a composition in a traditional perspective image with frontal perception with three horizon lines (a) and in an unconventional perspective image (wide-angle perspective-b), designed for the imagination, as a result of which the image of the drawings (b) acquired an unconventional form as an image with curved sides. The wideangle perspective allowed us to put down different accents of the same composition, in which the visual image can be applied to solve for different architectural problems than in the traditional perspective image with a frontal perception with three horizon lines. This exercise is of practical importance for solving a variety of promising problems in the development of architectural objects (multifunctional residential complexes and residential areas).

In general, the task, designed to develop combinatorial fantasy, associative, analog thinking, as well as spatial-compositional thinking, creates an artistic and expressive image of two different-scale architectural and geometric compositions (Figs. 8. a, b.).

The architectural and geometric composition of fantasy images, made in the technique of linear drawing with a constructive interaction of volumetric and spatial forms, enriches and 
expands creative architectural thinking in solving problems related to the large-scale (horizontal and vertical) division of various kinds of buildings and structures.

Creative work on a fantasy composition in achieving its expressive solution naturally requires searches, experiments with subject-spatial relations. One of the many experiments related to the interpretation of the «fantastic» is the «geonics» task, which consists in studying the forms of the inorganic world with the influence of geological and cosmochemical processes on them for the subsequent creation of a «fantasy» pattern by analogy.

It is pertinent to recall that since ancient times, mankind has borrowed architectural forms from organic and inorganic nature; for example, the Egyptian pyramids, the huts of the African Indians, resembling termite mounds, etc.

So, in accordance with geomorphology, the student has developed a new tectonic structure of the architectural ensemble through a linear-graphic drawing with a shifted centric perspective in the so-called «fantastic» environment as a prototype of a kind of new architecture (Fig. 9).

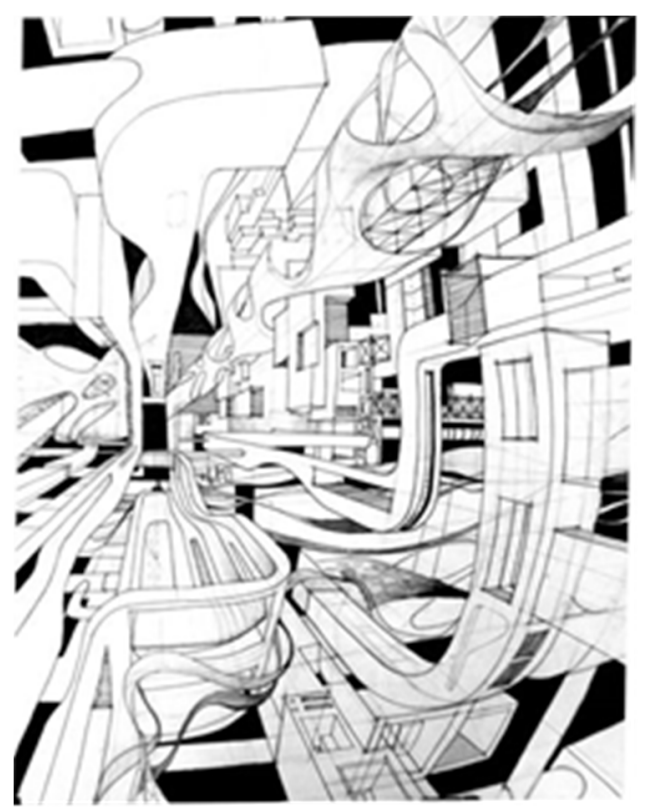

Fig. 9. Fantasy drawing.

It should be noted that, along with others, a collage of the urban environment can serve as a special method for solving compositional problems.

It is important to comprehend that the collage contains a procedural and creative content: it is not a mechanical depiction of nature in an application form, but its figuratively - creative elaboration, which does not consist in simple cutting and sequential drawing of forms, but is organically connected with the search for a composition, taking into account the format of the sheet, its color, the size of certain forms, as well as their location on the sheet.

The technological capabilities of the collage and its material make it possible to show creative compositional thinking: to mount forms, lay them out on a sheet, move, change places, replace one form with another, change their mutual values, present tone and forms as generalized ones. 
The creation of an urban environment by means of collage as an artistic-figurative abstraction requires solving one's own creative tasks that arise when performing any other graphic work.

Indeed, in essence, the technique of graphic representation in a variety of graphic compositions, in which it is important to be able to generalize the form, subordinate the secondary to the main, etc., in its functional application can be widely used not only in drawing, but also in architecture and design.

So, the artistic and architectural image, made using the collage technique (Fig. 10), expressively emphasizes the stylistic features and the ratio of volumetric-spatial scales, the compositional completeness of which is achieved by a bright light-tone elaboration of architectural forms.

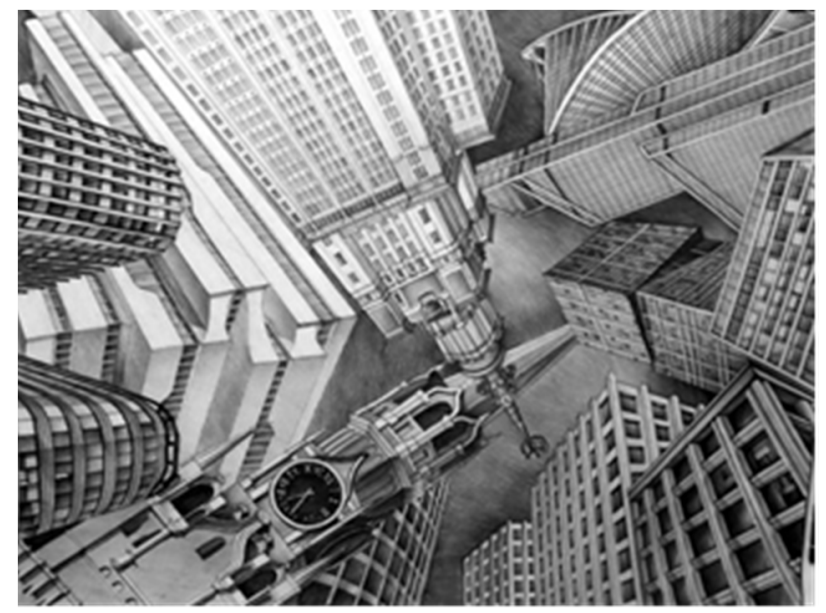

Fig. 10. Fantasy drawing.

\section{Conclusions}

Comprehension of the backbone interconnections of forms, methods, techniques, means and principles of teaching architectural drawing from nature and from «fantasy» in a complex enriches the performing technique of architectural drawing, compositional thinking, revealing potential creative possibilities and creating conditions for invariant training of architects who are able to solve urgent problems of architecture, adapting to the modern requirements of life, anticipating the future of architecture in a figurative representation, the core of which is the thought and creative position of the architect.

The study of the compositional diversity of architectural drawing in the relationship between images from nature and fantasy creativity in their unity is a great research and creative potential for finding discoveries, current and new forms in the architectural and artistic process of teaching future architects-innovators, in demand in the modern sociocultural space.

\section{References}

1. S. Nagpal, M. Singh, R. Singh, M. Vatsa, Discriminative shared transform learning for sketch to image matching, Pattern Recognition, 114, 107815 (2021).

2. V. Tkachev, Twilight of architecture, E3S Web of Conferences, 244, 05026 (2021)

3. E. Gubanova, The observer effect the artistic image as a metaphor for scientific interpretations of the natural world, Leonardo, 54(1), 71-78 (2021) 
4. S. V. Pryshchenko, Cultural heritage of a poster: Communicative and creative experience, Creativity Studies, 14(1), 18-33 (2021) DOI: 10.3846/cs.2021.12605

5. B. Liu, K. Song, Y. Zhu, A. Elgammal, Sketch-to-Art: Synthesizing Stylized Art Images from Sketches, Lecture Notes in Computer Science (including subseries Lecture Notes in Artificial Intelligence and Lecture Notes in Bioinformatics) 12627 LNCS, 207-222 (2021) DOI: 10.1007/978-3-030-69544-6_13

6. N. Vansieleghem, Tracing Lines: On the Educational Significance of Drawing, Studies in Philosophy and Education (2021)

7. M.G. Cianci, D. Calisi, S. Colaceci, M. Molinari, Imagination and representation: Metaphor of designing thought, Advances in Intelligent Systems and Computing, 1140, 369-382 (2020) DOI: 10.1007/978-3-030-41018-6_31

8. J. Seo, H. Park, S. Coho, Inference of drawing elements and space usage on architectural drawings using semantic segmentation, Applied Sciences (Switzerland),10(20), 7347, 1-14 (2020) DOI: 10.3390/app10207347

9. Y. I. Arutyunyan, Actual Problems of Theory and History of Art, Visual Interpretation: On the Study of European Architectural Graphics of $17^{\text {th }}-18^{\text {th }}$ Centuries, 10, 22-31 (2020)

10. M. G. Cianci, D. Calisi, S. Colaceci, M. Molinari, Imagination and representation: Metaphor of designing thought, Advances in Intelligent Systems and Computing, 1140, 369-382 (2020) DOI: 10.1007/978-3-030-41018-6_31

11. N. -J.Shih, Y.-T. Tsai, A computer-aided study of cartesian and photogrammetry modeling of paper architecture, Computing in Civil and Building Engineering, 1201 208 (2000) DOI: 10.1061/40513(279)26

12. F. A. Brunetti, Observation, Drawing, Modeling. Elements of a Cognitive Process Between Analogic and Digital for Design Learning, Lecture Notes in Networks and Systems, 88, 13-30 (2000) DOI: 10.1007/978-3-030-29796-1_2

13. F. Lianto, Grounded Theory Methodology in Architectural Research Journal of Physics: Conference Series, 1, 012102 (2019)

14. S. Skandarajah, Into the Clouds of Rakuchu Rakugai Zu: Eastern-Western Drawing Tolerance Critiqued through Speculative Drawing Practices, Architecture and Culture, 7(1), 129-147 (2019)

15. D. A. Cattaneo, J. P. Cutruneo, The outside is always an inside»: the idea of space and its theoretical heritage in "Toward an architecture», Journal of Architecture and Urbanism, 40(3), 250-258 (2016)

16. Hougaard, A.K. Architectural drawing - an animate field. Open House International (2015), 40(2), pp. 44-53.

17. F. Lianto, Grounded Theory Methodology in Architectural Research, Journal of Physics: Conference Series, 1179(1), 012102 (2019)

18. I. Bobbink, S. de Wit, Landscape Architectural Perspectives as Agent for Generous Design, Research in Urbanism Series, 6, 129-149 (2021)

19. The architecture of the world. Encyclopedia of Architectural Styles (SZKEO, SPb, 2009)

20. A. V. Ikonnikov, G. P. Stepanov, Basics of architectural composition (Publishing house «Art», Moscow, 1971)

21. Le Corbusier, The architecture of the twentieth century (Publishing house «Progress» Moscow, 1970)

22. T. G. Maklakova, Function-construction-composition (Publishing house ASV, Moscow, 2002)

23. L. M. L. Arana, Real fictions: Collage, photo manipulation, and architectural image in the digital era [Real Fictions. Collage, fotomanipulación e imagen arquitectónica en la era digital], ZARCH, 9, 106-121 (2017) 
24. A. Tostões, Fantasy must be brought back into architecture [La fantasia debe ser devuelt a al aarquitectura], RA Revista de Arquitectura, 19, 19-24 (2017)

25. S. Mikhailov, R. Khafizov, A. Mikhailova, N. Nadyrshine, L. Nadyrshine, Supergraphics as a project and artistic method in design of a modern city, IOP Conf. Ser.: Mater. Sci. Eng., 890, 012003 (2020) DOI: 10.1088/1757-899X/890/1/012003

26. I. Shakirova, Three waves of theoretical architecture and design, IOP Conf. Ser.: Mater. Sci. Eng., 890, 012010 (2020) DOI: 10.1088/1757-899X/890/1/012010

27. K. Nadyrova, D. Nadyrova, Identity of the architecture of mosques in Russia in the late XX-early XXI century (as exemplified by Tatarstan), IOP Conf. Ser.: Mater. Sci. Eng., 890, 012023 (2020) DOI: 10.1088/1757-899X/890/1/012023

28. M. Smolova, D. Smolova, Images of associative psychology as a generator of architectural education ideas, IOP Conf. Ser.: Mater. Sci. Eng., 890, 012169 (2020)

29. DOI: $10.1088 / 1757-899 X / 890 / 1 / 012169$ 